\title{
RHEOLOGICAL RELATIONSHIP TO SEDIMENT DEPOSITION RATE IN MACAN WEIR SEDIMENT TRAPS
}

\author{
${ }^{*}$ Muhammad Isnaeni ${ }^{1}$, Muhammad Syahril Badri Kusuma ${ }^{2}$ and Joko Nugroho ${ }^{2}$ \\ ${ }^{1}$ Doctoral Program of Water Resources Engineering, Faculty of Civil and Environmental Engineering, \\ Institut Teknologi Bandung, Indonesia; ${ }^{2}$ Water Resources Engineering Research Group, Faculty of Civil and \\ Environmental Engineering, Institut Teknologi Bandung, Indonesia
}

*Corresponding Author, Received: 17 Oct. 2021, Revised: 07 Nov. 2021, Accepted: 23 Nov. 2021

\begin{abstract}
Irrigation canals require a sediment trap to control not-allowable sediment deposits in the primary irrigation canals to maintain the highest paddy yield. The not-allowable sediment deposit for Cimacan River, not only non-cohesive sediment (dia $>0.07 \mathrm{~mm})$ as for regular river, but also cohesive sediments $($ dia $<0.07 \mathrm{~mm}$ ) that could be cemented rapidly under the laminar flow condition and then potentially decrease the performance of irrigation canals. This paper presents the resulting study of the rheologic characteristic of the cemented bed sediments and the threshold velocity related to the sediment cementing process of irrigation canals in the Cimacan River. The study was conducted based on field and secondary data. The geological investigation had been carried out and tested to obtain grain-size distribution, sediment stratification, and water temperature in the Cimacan river tested in 2017 and 2019. Secondary data is taken to support the comparison study. Based on this study, it is found that the cemented sediment could be flushed only when the average velocity of the lower layer of the flow is greater than the threshold velocity of cementing occurrence. In this case, the $\mu$ movement curve as a function of viscosity $I_{v}$ that could reach beyond the range of $3 \times 10^{-5}<I_{v}<2$ had shown the validation of local rheology models. Meanwhile, the range of $I_{v}<3 \times 10^{-5}$ could be described as transitions flow where $\mu \rightarrow \mu_{\mathrm{s}}$ could be expected for flushing the sediment layer. Numerical models can easily calculate this rheology regime. However, to achieve maximum results, it is necessary to develop a physical model supported by a binocular microscope.
\end{abstract}

\section{Keywords: Rheology, Sediment, Non-cohesive, Sediment traps}

\section{INTRODUCTION}

Indonesia is a developing archipelagic country where a land-use change of its most river catchment area become a common predominant phenomenon for national agricultural, especially paddy, development policy. Land-use change tends to decrease the dependable flow for irrigation and increase the extreme discharge [1] so that the annual yield of paddy fields tends to decrease. Furthermore, land-use change tends also to increase sedimentation problems in the rivers and reservoirs [2],[3],[4]. Thus, land-use change has become a common phenomenon that decreases paddy fields and the annual yield of the paddy field.

Irrigation modernization is seen as a necessity for further efforts to overcome threats to the sustainability of irrigation countries. The threat comes from various aspects, such as the critical water demands for efficient agricultural production (FAO). A considerable effort is required to be done to improve irrigation operations. A desilting basin is a temporary sediment control structure to intercept sediment-laden runoff and to retain the sediment. It aims to detain sediment-laden runoff from the disturbed area for sufficient time and allow a majority of the deposit to settle within the sediment trap [5].
Erosion occurring upstream of Citarum Watershed must be treated as necessary because the longer that sediment accumulates, the greater reduction in water capacity at Citarum. Soil erosion is a global environmental problem that threatens the lives of the majority of small farmers. On land cultivation, soil conservation requires specific types of vegetation supported by an efficient strategy for controlling soil loss. Approximately $80 \%$ of current agricultural land is degraded due to global soil erosion. The practise of sustainable agriculture is challenged by severe soil erosion and reduced onfarm productivity of the soil, resulting in food insecurity [6].

Fine, cohesive sediment suspensions are a common feature of estuarine environments. Generally, multilayer models are used to describe the vertical distribution of such sediments. Such conceptional models normally distinguish at least high suspended sediment concentrations (SSCs) as a topmost layer and a consolidated bed layer, often including an intermediate, fluid mud layer. Rheological and sedimentological properties are rarely included in these models. Many attempts have been made to determine the effects of nonNewtonian rheological properties on relatively solid motion through fluids. Sediment transport involves 
the entrainment and movement of granular materials by shifting fluid flow [7].

Fluid mobilized sediment transport dynamics are an attractive solution, as they occur on the surface between fine materials and fluid flow. A relevant example is the flow of a non-Newtonian fluid through bedload flow and sedimentation of particle suspension.

In a weir, in this case, a sediment trap becomes one unit with the main structure. Sediment traps are built to avoid non-cohesive sediments (dia $>0.07 \mathrm{~mm}$ ) entering an irrigation scheme. Under unavoidable circumstances, cohesive sediments (dia $<0.07 \mathrm{~mm}$ ) will enter the irrigation scheme by controlling the flow rate and slope of the base of the irrigation canal in accordance with applicable planning criteria. The problem that often arises is not continuous in a flushing condition in sediment traps that have been set time periodically. Delay in Operational and Maintenance (O\&M) officers in flushing due to non-technical and technical problems, causing trapped sediments to be rapidly cemented [8].

This study examined the nature of rheology based on sediment deposition rate in sediment traps, which is related to the rheological nature of the sediment itself. Sediment can settle in a laminar flow. The location of the study on the contribution of this study is Macan weir, in Subang Regency. This weir service a technical irrigation area of 9,670 ha, where the current condition of perimeter section area is reduced by $\pm 35 \%$, caused by sedimentation. The existing conventional plan will construct sediment traps rectangular shape located right side of the head structure.

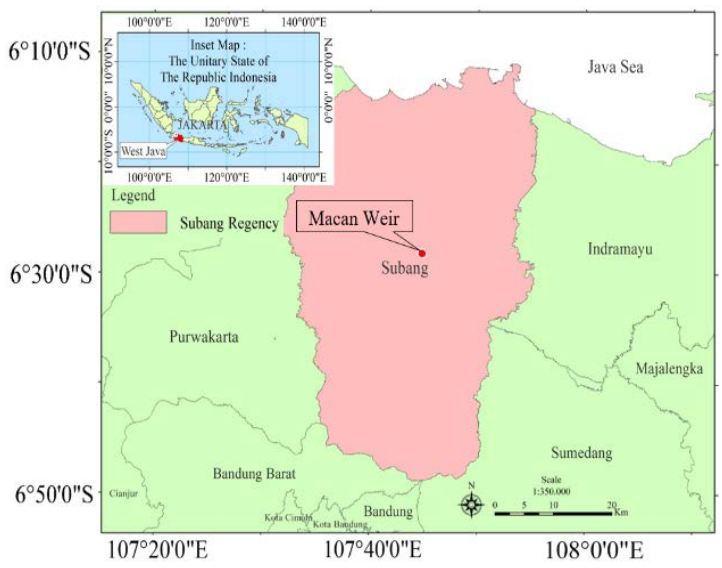

Fig.1 Macan weir, located in West Java, Indonesia

The flushing way outlet cross over the national bridge road. This case is an exciting point to improve the shapes of sediment traps. In this study, as a first step in determining the exact equation in sediment deposition rate, some soil investigation data have been obtained as a reference and to choose the existing and cemented sediment conditions at the bottom of the main canal in the weir intake structure [8].

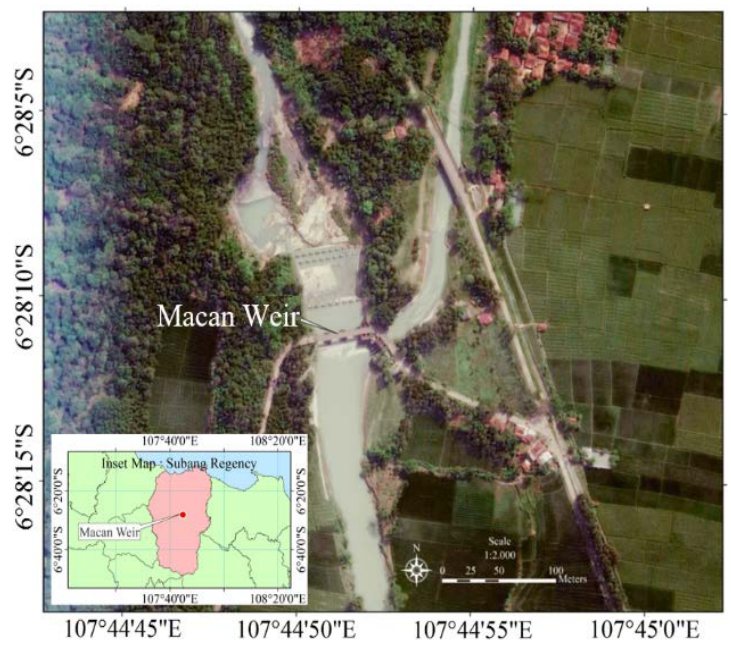

Fig.2 Layout of Macan weir

The study of the rheological behavior of natural mud is concerned with flows or deformations of a mud sample experiencing an external forcing. Variable amounts of river water are trapped in the mineral structure of natural mud by attracting force. As a result, natural mud shows viscous behaviors through a varying range of water content. When dried, mud can be hardened and show pure elastic behavior. However, natural mud is a viscous-elastic material in its natural state. It is important to have an adequate constitutive equation to describe natural mud's viscous and elastic responses to various loads.

Unfortunately, there is no proper sampling in situ method available to measure the rheology of naturally deposited mud. Meaningful in situ measurements are difficult to perform without disturbing the natural silt deposited in the bottom layer of the canal. Mud samples used in laboratory tests often are severely disturbed.

Therefore, the microstructure of mud samples in laboratory tests may significantly differ from that of the natural mud deposited in the seabed. In laboratory studies, the field sample must be handled carefully to keep the test conditions as close to the natural conditions as possible. Factors that we need to considerer include seawater salinity, sediment concentration, consolidation time, temperature, etc. [9].

Fig.3 describes the layout of the study location, and as shown in Fig.4, sedimentation has occurred in the main canal and reduced the wet perimetersectional area. Especially sediment from the river accumulated will harden quickly if not flushed out periodically by operational and maintenance officers. 


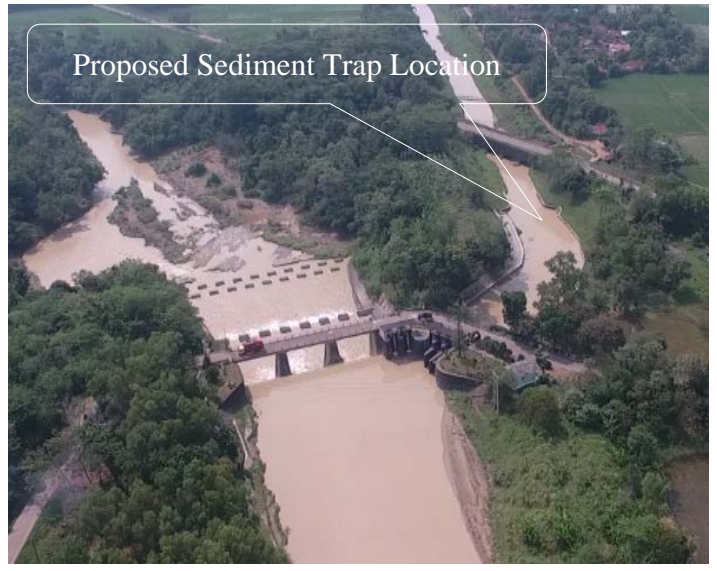

Fig.3 Macan weir view from the air upstream to downstream

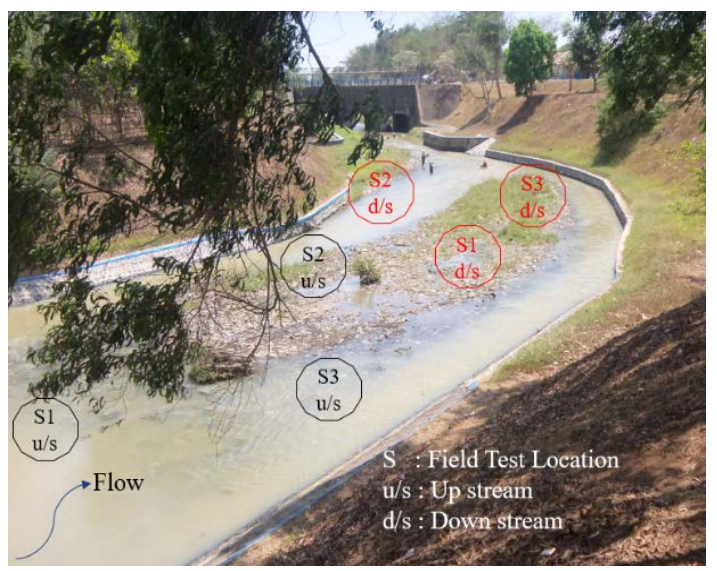

Fig.4 Sedimentation has filled nearly half of the wet perimeter section of the Macan's main canal and file test location

This study improves the vortex desilting basin sediment traps that will gradually test their hydraulic behavior. Obtaining the nature of sediment rheology is very important because future research aims to find out the flushing force to flush non-cohesive sediment.

Natural mud samples used in this study were taken from two locations in Macan weir. Where each three-field test in the upstream and downstream area of the primary canal. Some basic soil properties are summarized in Table 1.

\section{BACKGROUND}

Understanding the transport of cohesive sediments in complex flow conditions is important in general irrigation-related structures associated with irrigation canals. Inadequate representation of the physical properties of cohesive sediments can lead to greater uncertainty in transport sediment prediction than inadequate representations in hydrodynamics.
As we know, this precipitating mud consists of viscous-elastic material under natural circumstances. It is necessary to look for constitutive equations to describe the viscous and elastic response from natural sludge to various load distributions. Unfortunately, there is currently nothing good in the method for measuring the rheology of naturally stored sludge. Meaningful measurement is difficult to do without disturbing the natural mud stored on the riverbed. Sediment samples taken in laboratory tests are often severely impaired. Therefore, in laboratory tests, the microstructure of sludge samples can be significantly different from raw sludge stored at the riverbed [10].

Among the different sediment transport regimes, bedload transport is of significant importance as it represents an essential contribution to river morphology evolution. Accordingly, predicting the sediment transport rate under turbulent bedload conditions is fundamental for preventing environmental risks associated with floods and scouring. From a physical point of view, bedload transport corresponds to the dynamic response of a granular bed submitted to fluid shear stress. In contrast to suspended load, bedload is defined as the part of the sediment load occurring close to the granular bed in which particles are in permanent or intermittent contact with the bed [11].

The flow that enters the irrigation scheme that transports the sediment is shown in plastic flow and not elastic deformation when the working force is applied. Newtonian fluids can be characterized by a single viscosity coefficient at the water temperature in this canal. Although viscosity can change with temperature changes, Newtonian fluids do not experience changes in average strain. Only a small percentage of fluids exhibit the properties of constant viscosity, such as Newtonian fluids. Most fluids, called non-Newtonian fluids, exhibit changes in viscosity as average strain changes.

It is well-known that the most important parameter describing particles moving in fluids is their settling velocity, which is a function of the physical properties of the particles and the rheological behavior of the fluid. It is useful to express this velocity as a function of two dimensionless numbers, the drag coefficient and the Reynolds Number [12].

As a result, sediment cemented on the main canal entering through the intake gate will be difficult to demolish and reduce the wet perimeter section on the main canal. The cement sediment on this laminar flow will be connected based on primary data obtained from sediment transport. The study also provides information to operational officers to find out in a certain unit of time, and the sediment was cemented very difficult flush in outlet canal [13]. 


\section{METHODS}

Previously, research has been conducted for sediment deposition rate at this location by choosing a Fergusson-Church (2004) that resulted in $0.922 \mathrm{~cm} / \mathrm{s}$ for particles $>0.007 \mathrm{~mm}$. The sedimentation deposition rate at the study site has been calculated with $0.18 \mathrm{~m}^{3} /$ day [8].

This research has started by taking data on sediment property obtained from primary data taken in 2019 tested at the Laboratory of Engineering
Geology, Padjajaran University, with the known sedimentation properties and physical properties contained therein. The gradation of the sediment was taken by comparing the data around the study site, such as on the Cibeet and Ciasem rivers, see Fig.5. The sediment properties in the Macan weir sediment trap were taken in upstream (3 samples) and downstream (3 samples) sampling points, with laboratory test results at $20^{\circ} \mathrm{C}$ water temperatures summarized in Table 1 below:

Table 1 Result of sediment laboratory test

\begin{tabular}{|c|c|c|c|c|c|c|c|}
\hline No & $\begin{array}{c}\text { Sample } \\
\text { Location }\end{array}$ & $\begin{array}{l}\text { Density } \\
\rho_{\mathrm{s}=\mathrm{kg} / \mathrm{m}}{ }^{3}\end{array}$ & $\begin{array}{c}\text { Sieve } \\
\text { Analyzed } \\
\# 200= \\
<0.007 \mathrm{~mm} \\
(\%)\end{array}$ & $\begin{array}{c}\text { Mass } \\
\text { Concentration } \\
\mathrm{S}\left(\mathrm{kg} / \mathrm{m}^{3}\right)\end{array}$ & $\begin{array}{c}\text { Consolidation } \\
\text { Time } \\
\text { (minute) }\end{array}$ & $\begin{array}{c}\text { Volume } \\
\text { Concentration } \\
\mathrm{C}_{\mathrm{v}}\end{array}$ & $\begin{array}{c}\text { Mud } \\
\text { Density } \\
\rho_{\mathrm{s}=\mathrm{kg} / \mathrm{m}^{3}}\end{array}$ \\
\hline 1 & $\mathrm{u} / \mathrm{s}$ S1 & 2672 & 33.1 & 910 & 5 & 0.37 & 1498 \\
\hline 2 & $\mathrm{u} / \mathrm{s}$ S2 & 2681 & 34.3 & 654 & 5,10 & 0.29 & 1543 \\
\hline 3 & $\mathrm{u} / \mathrm{s}$ S3 & 2699 & 34.5 & 577 & 5 & 0.22 & 1511 \\
\hline 4 & $\mathrm{~d} / \mathrm{s}$ S1 & 2710 & 35.6 & 1011 & 5 & 0.34 & 1412 \\
\hline 5 & $\mathrm{~d} / \mathrm{s}$ S2 & 2716 & 36.5 & 674 & 5 & 0.24 & 1432 \\
\hline 6 & $\mathrm{~d} / \mathrm{s}$ S3 & 2739 & 39.4 & 593 & 5 & 0.19 & 1411 \\
\hline
\end{tabular}

(Laboratory of Engineering Geology, Padjajaran University, 2019)

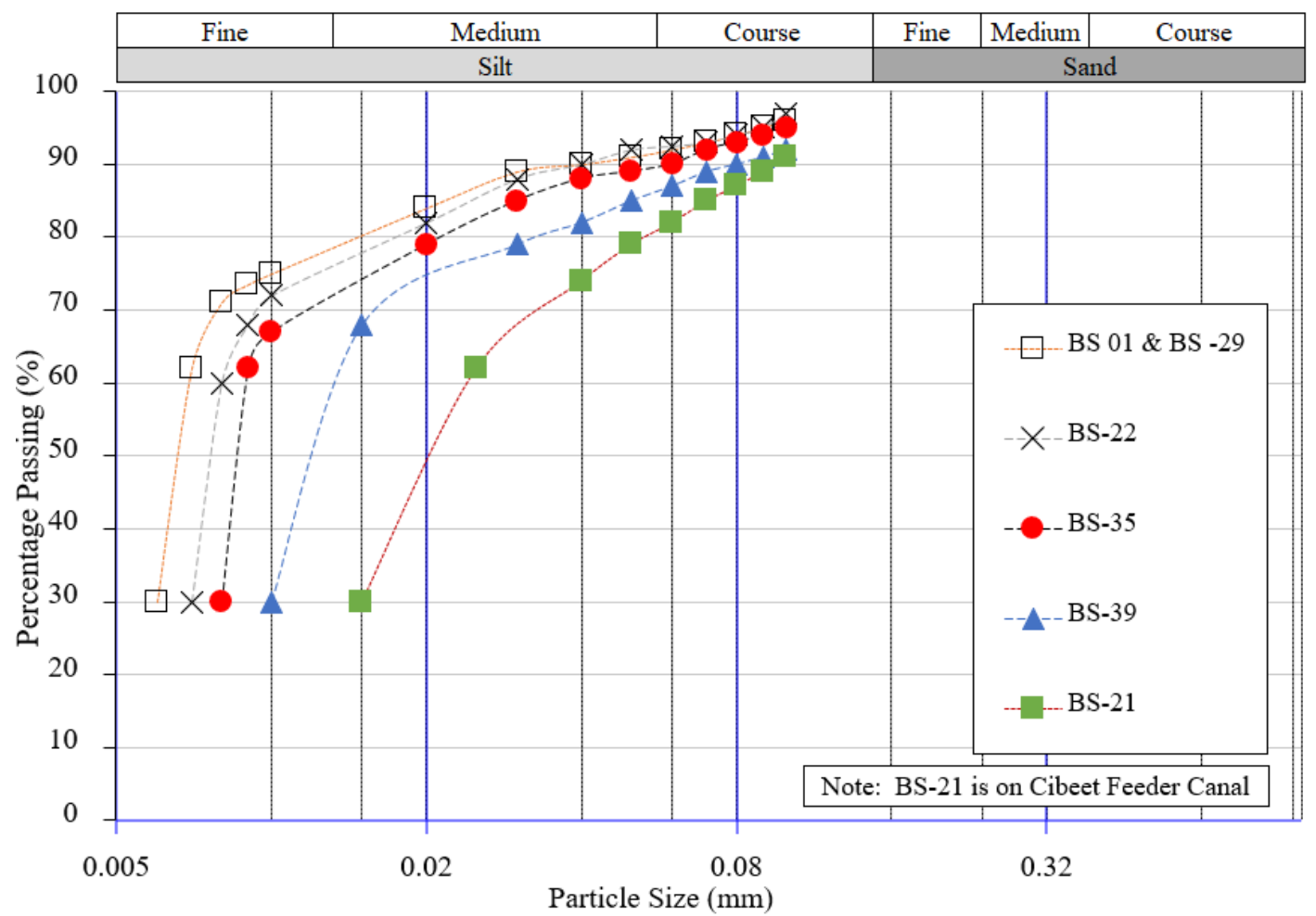

(ICWRMP Preparation Project, BBWS Citarum, 2018-Redrawing Chart 2021)

Fig.5 Analyzed sediment gradation at Cibeet and Cimacan river

Survey of sediment transport on the Cimacan and Cibeet Rivers in 2018 by PMMJIS-WSIMP-II Sinotech Co., Ltd \& Associates, 80\% of sediment material entered the Cibeet Cimacan Rivers was Silt $0.004-0.062 \mathrm{~mm}$. From the sediment properties and sediment classifications obtained from the primary and secondary data above, the study modelled two equations. By entering sediment property data in Table 1, it uses Eq. (3), (5) and (7) plotted to find out $\tau, \dot{\gamma}$, and $\mathrm{I}_{\mathrm{v}}$. 


\section{RESULT AND DISCUSSION}

Several experimental studies have been carried out to predict the completion of spherical particles in non-Newtonian flows. One of these studies, Kelessidis and Mpandelis in 2004, produced explicit equations relating to the size of spherical particles with a deposition rate of resolution with a good approach in various practical Reynolds numbers in engineering with experimental data parameters. The contribution of this study is the acquisition of an explicit theoretical cementation acceleration relationship so that the maximum time limit of flushing of sediments [14].

\subsection{Rheological models for steady or oscillatory mudflows}

If mud is treated as continuum media, the following equations can be used to model the mudflow [12]:

$$
\begin{gathered}
\frac{\partial_{u_{i}}}{\partial x_{i}}=0 \\
\rho \frac{D u_{i}}{D_{t}}=-\frac{\partial p}{\partial x_{i}}+\frac{\partial \tau_{i j}}{\partial x_{j}},
\end{gathered}
$$

where $\mathrm{u}_{\mathrm{i}}$ is the velocity component in $\mathrm{x}_{\mathrm{i}}$ - direction, $\mathrm{D}_{\mathrm{t}}$ is the time, $\mathrm{p}$ is the dynamic pressure in a mudflow, and $\rho$ the mud density. The stress tensor $\tau_{\mathrm{ij}}$ is related to the mud property by a certain constitutive equation. Depending on the nature of the mudflow, a large number of constitutive equations are available for the stress tensor $\tau_{\mathrm{ij}}$. It is usually assumed that mud samples are isotropic. Under this assumption, the constitutive equation for the stress tensor $\tau_{\mathrm{ij}}$ can be constructed from a onedimensional rheological experiment. For onedimensional mudflow, the simplest relation between the shear stress and the deformation can be described by $\tau=\tau(\gamma, \dot{\gamma})$ where $\gamma$ and $\dot{\gamma}$ are shear strain and shear rate, respectively. The two models used in the study were briefly reviewed first for the initial stages [15].

The time of dependent deformation of mud/materials is called the rheology, The relationship between deformation and flow due to certain shear stress with shear force $\tau$. Because the flow of sludge is in the fluid, the behaviour of the mudflow is influenced by two rheological parameters: the yield of stress $\tau_{\mathrm{y}}$ and viscosity $\eta$ of a fluid that immobilized lower than $\tau_{\mathrm{y}}$, the sediment is in a plastic condition and instead becomes a fluid [16].

Therefore, sludge flow is categorized as a NonNewtonian fluid. In these viscous fluid conditions, the pore number is relatively high. As shown in Fig.6 illustrates the relationship between shear force $\tau$ and shear strain rate $\dot{\gamma}$. Viscosity states the viscosity of the fluid and is the gradient of the curve; for the analysis of the movement of mudflow, can be used Bingham's model [17].

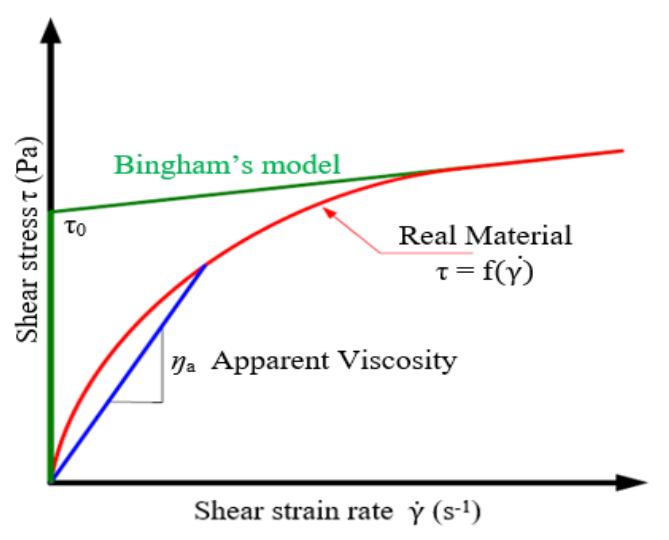

Fig.6 Relationship between shear force $\tau$ and shear strain rate $\dot{\gamma}$

\subsection{Rheology of steady mudflows}

One of the widely-used models for steady mudflows is the Herschel-Bulkley model or generalized Bingham plastic model [18]. HerschelBulkley model is a two-parameter rheological model, which relates the shear rate $\dot{\gamma}$ to the shear stress $\tau$ by:

$$
\tau=\tau_{0}+\eta_{\mathrm{B}} \dot{\gamma}^{\mathrm{n}},|\tau| \geq \tau_{0} \text {, and } \dot{\gamma}=0,|\tau|<\tau_{0}
$$

Refer to Eq. (3) $\tau_{0}$ is the so-called yield stress (the shear stress at $\dot{\gamma}=0), \eta_{\mathrm{B}}$ is a parameter related to the mud viscosity, and $\eta$ is the so-called flow index. When $\mathrm{n}<1$, mud exhibits shear-thinning behavior; when $\mathrm{n}>1$, mud exhibits a shear-thickening behavior. For the Herschel-Bulkley model, an apparent viscosity $\eta_{a}$ is defined by Eq. (4) as follow:

$$
\eta_{\mathrm{a}}=\frac{\tau_{0}}{\dot{\gamma}}+\eta_{B} \dot{\gamma}^{n-1},|\tau| \geq \tau_{0}
$$

There is no definition for the apparent viscosity when $|\tau|>0$, in three common cases that occur in laminar flows, it can be adopted from the HerschelBulkley model when $\tau_{0}=0$ and $n \neq 1$, a Newtonian models when $\tau_{0}=0$ and $n=1$, and Bingham's plastic model when it occurs $\tau_{0}>0$ and $n=1$. The Bingham model is used as a common mathematical model of mud flow in drilling engineering and in handling slurries [19].

In other literature [9], the Dual-Bingham method in the same case proposes equations for connecting $\tau$ and $\dot{\gamma}$ as follows:

$$
\left\{\begin{array}{c}
\tau=\tau_{0}+\eta_{0} \dot{\gamma}, \dot{\gamma}<\dot{\gamma} c \\
\tau=\tau_{\infty}+\eta_{\infty} \dot{\gamma}, \dot{\gamma} \geq \dot{\gamma} c
\end{array},\right.
$$

Where $\tau_{0}$ is Dual-Bingham yield-stress and $\tau_{\infty}$ is Dual-Bingham apparent yield-stress. So is viscosity 
$\eta_{0}$ and $\eta_{\infty}$. Shear stress $\dot{\gamma} c$ is obtained from the following equation:

$$
\dot{\gamma} C=\frac{\tau_{\infty}-\tau_{0}}{\eta_{0}-\eta_{\infty}}
$$

\subsection{Dry-granular flow rheology relationship and suspended flow}

Boyer's previous research conducted a series of simple shear experiments that determined the relationship $\eta\left(\mathrm{I}_{\mathrm{v}}\right)$. To cases of neutral floating particles $\left(\rho_{\mathrm{p}} / \rho_{\mathrm{f}}=1\right)$ immersed in a viscous liquid. The study linked the rheological framework of drygranular and suspended flow [20]. Measurements with mass parameters show that friction can be described as the transition from dry-granular rheology to suspended flow rheology (where the contact of the particles is completely ignored):

$$
\begin{aligned}
\mu\left(I_{v}\right) & =\mu_{d r y}\left(I_{v}\right)+\mu_{\text {susp }}\left(I_{v}\right) \\
& =\mu_{s}+\frac{\mu_{d}-\mu_{s}}{\frac{I_{0}}{I_{v}}+1}+I_{v}+\frac{5}{2} \emptyset_{c} I_{v}^{\frac{1}{2}}
\end{aligned}
$$

Where $\mathrm{I}_{0}=0.006, \mu_{\mathrm{s}}=0.32$, and $\mu_{\mathrm{d}}=0.7$. The values for $\mu_{\mathrm{s}}$ and $\mu_{\mathrm{d}}$ are within the classical range observed for dry granular flows [21]. While $\mathrm{I}_{0}$ it seems to depend on the definition of $t_{\text {micro }}$. The term $\emptyset_{c}$ is the packing fraction in which the viscosity diverges in suspension experiments, found to be 0.585 by Boyer [20]. The results of calculations with Herschel-Bulkley from laboratory data resulted in very low sediment concentrations.

Dual-Bingham can provide a satisfactory description of the flow curve. However, other sediment samples cannot use a single model/equation to describe the flow curve measured. Although it is not possible to use a single Herschel-Bulkley model to describe the flow curve, it can identify two flow regimes (low shear rate regime and high shear rate) and use the Bingham model for each regime, i.e. to use the Dual-Bingham model described by Eq. (5). In the plot log Fig.8, the difference between the curve and the measured data is magnified in the low shear level region. It can be observed that the shear pressure predicted by both models is slightly greater than that measured at low shear rates $\left(\dot{\gamma}<0.01 \mathrm{~s}^{-1}\right)$ especially for high concentration mud samples, suggesting that both models slightly more predicted the yield pressure.

The curve plot at the study site is shown in Fig.7 Shear Stress Dual-Bingham $\tau_{0}$ approaches Shear Stress which is spawned to flush out the sediment at the base of the sediment trap. The results of laboratory tests that have been calculated shear stress and viscosity are presented in the following Table 2 and Table 3:

Table 2 Herschel-Bulkley parameters model

\begin{tabular}{cccccc}
\hline No & Location & $\tau_{0}\left(\mathrm{~N} / \mathrm{m}^{2}\right)$ & $\eta_{0}\left(\mathrm{~N} . \mathrm{s} / \mathrm{m}^{2}\right)$ & $\tau_{\infty}\left(\mathrm{N} / \mathrm{m}^{2}\right)$ & $\eta_{\mathrm{o}}\left(\mathrm{N} . \mathrm{s} / \mathrm{m}^{2}\right)$ \\
\hline 1 & $\mathrm{u} / \mathrm{s} \mathrm{S} 1$ & 40.21 & 27.65 & 135.65 & 0.07 \\
2 & $\mathrm{u} / \mathrm{s} \mathrm{S} 2$ & 3.43 & 3.54 & 11.21 & 0.01 \\
3 & $\mathrm{u} / \mathrm{s} \mathrm{S} 3$ & 1.85 & 4.34 & 5.40 & 0.00 \\
4 & $\mathrm{~d} / \mathrm{s} \mathrm{S} 1$ & 41.87 & 201.20 & 198.21 & 1.43 \\
5 & $\mathrm{~d} / \mathrm{s} \mathrm{S} 2$ & 3.53 & 3.40 & 6.30 & 0.08 \\
6 & $\mathrm{~d} / \mathrm{s} \mathrm{S} 3$ & 2.65 & 1.99 & 4.87 & 0.01 \\
\hline
\end{tabular}

Table 3 Dual-Bingham parameters model

\begin{tabular}{ccccccc}
\hline No & Location & $\tau_{0}\left(\mathrm{~N} / \mathrm{m}^{2}\right)$ & $\eta_{0}\left(\mathrm{~N} . \mathrm{s} / \mathrm{m}^{2}\right)$ & $\tau_{\infty}\left(\mathrm{N} / \mathrm{m}^{2}\right)$ & $\eta_{\mathrm{o}}\left(\mathrm{N} . \mathrm{s} / \mathrm{m}^{2}\right)$ & $\gamma_{\mathrm{c}}(\mathrm{l} / \mathrm{s})$ \\
\hline 1 & $\mathrm{u} / \mathrm{s} \mathrm{S} 1$ & 40.21 & 27.65 & 135.65 & 0.07 & 10.21 \\
2 & $\mathrm{u} / \mathrm{s} \mathrm{S} 2$ & 3.43 & 3.54 & 11.21 & 0.01 & 4.76 \\
3 & $\mathrm{u} / \mathrm{s} \mathrm{S3}$ & 1.85 & 4.34 & 5.40 & 0.00 & 1.65 \\
4 & $\mathrm{~d} / \mathrm{s} \mathrm{S} 1$ & 41.87 & 201.20 & 198.21 & 1.43 & 9.91 \\
5 & $\mathrm{~d} / \mathrm{s} \mathrm{S} 2$ & 3.53 & 3.40 & 6.30 & 0.08 & 3.65 \\
6 & $\mathrm{~d} / \mathrm{s} \mathrm{S3}$ & 2.65 & 1.99 & 4.87 & 0.01 & 0.902 \\
\hline
\end{tabular}




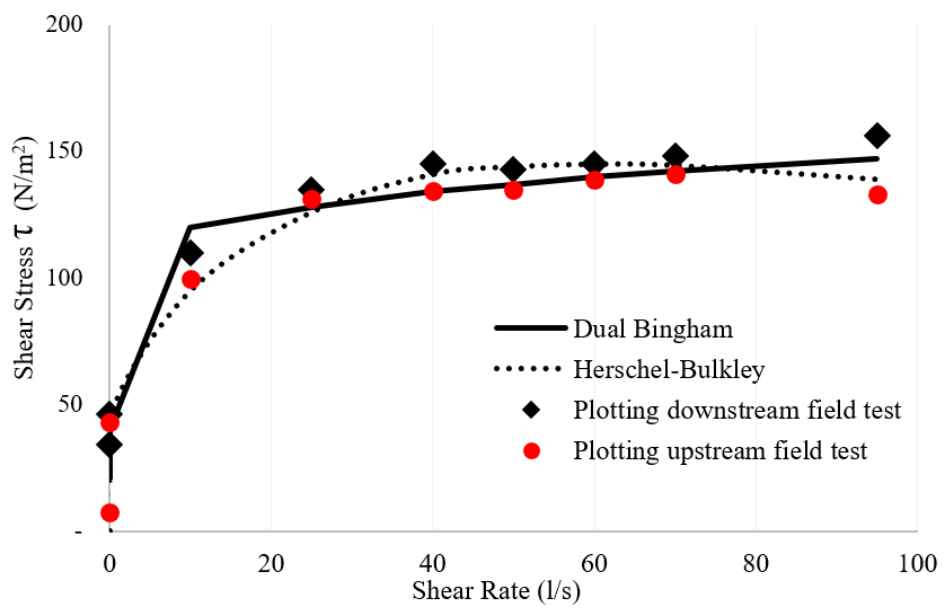

Fig.7 Herschel-Bulkley and Dual-Bingham parameters model plotted by laboratory tests result

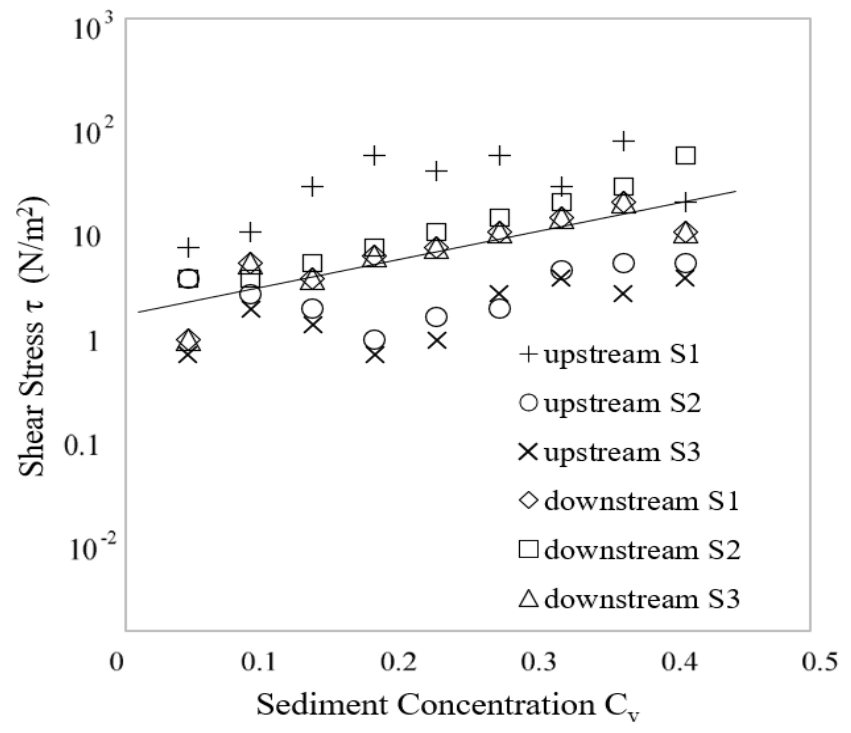

Fig.8 Dual-Bingham yield stress and initial viscosity

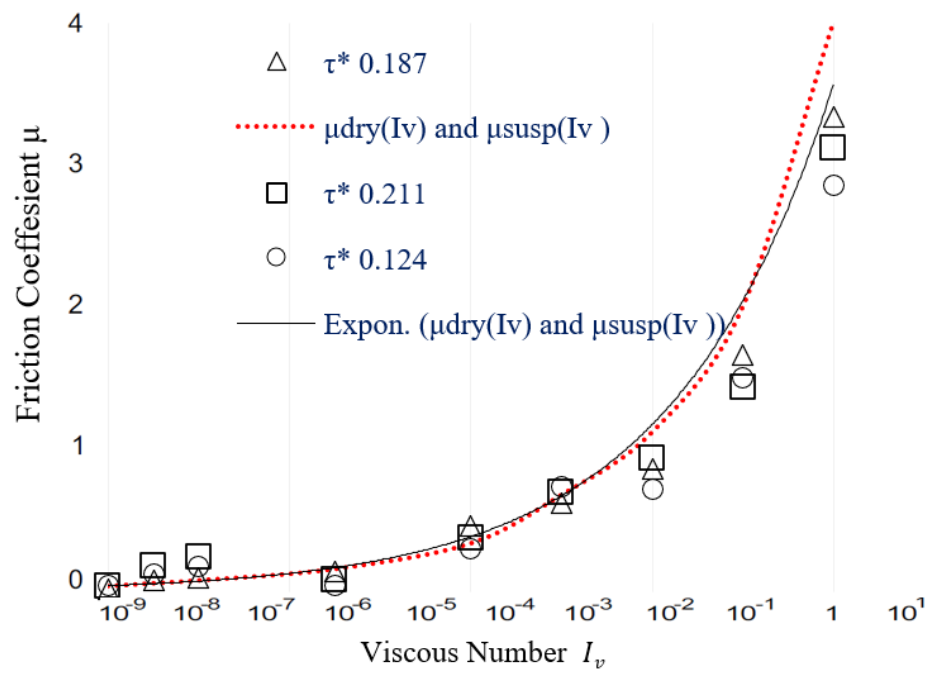

Fig.9 Friction coefficient $\mu$ as a function of $I_{v}$, computed using the confining pressure $P_{0}=0.1\left(\rho_{p}-\rho_{f}\right)_{g d}$ that accounts for particle weight 
As shown in Fig.9, physically, the sediment concentrate of $\mathrm{C}_{\mathrm{v}}$ sediment volume reflects the distance between the sediment particles; that is, a decrease in $C_{v}$ will increase the distance between the sediment particles and thus weaken the force between the sediment particles. The results of the analysis obtained are determined by adjusting the flow curve as measured by the same rheological model and thus can be compared because the results determined by the extrapolation method largely depend on the rheology model used to extrapolate.

\section{CONCLUSIONS}

Plots the frictional friction curve as a function of the viscous number $I_{v}$, which is calculated using the pressure $\mathrm{P}_{0}=0.1\left(\rho_{\mathrm{p}}-\rho_{\mathrm{f}}\right)_{\mathrm{gd}}$ contributing as particles $>0.007 \mathrm{~mm}$ (See Fig.9). The dashed red curves represent dry $\mu_{\text {dry }}\left(\mathrm{I}_{\mathrm{v}}\right)$ and $\mu_{\text {susp }}\left(\mathrm{I}_{\mathrm{v}}\right)$ respectively, and the black line represents the relationship in the test data with a range of $3 \times 10^{-5} \leq I_{v} \leq 2$, which is the result of Eq.(7), in where $\emptyset_{c}$ is the only fixed parameter.

As a result, $\mathrm{I}_{\mathrm{V}}<3 \times 10^{-5}$, there is no convergence of friction coefficients with static values $\left(\mu=\mu_{\mathrm{s}}\right)$. Contrary, $\mu$ decrease continuously below the $\mu$ with diminishing $I_{v}$. After analyzing the rheological properties of these sediments, the simple DualBingham model is simply to apply than the Herschel-Bulkley model. Analysis shows that stable and dynamic rheological properties can be expressed as precise exponential functions of sediment volume concentration, with empirical parameters depending on size distribution, clay content, organic content, and mineral composition. Sediment samples on the downstream side are more rapidly cemented. It takes shear stress of $153 \mathrm{~N} / \mathrm{m}^{2}$ to flush out the sediment that has been tapped within six (6) days.

The rheological nature of the steady flow of sedimentary mud and oscillations at the study site cannot and is very difficult to break with its original. The interrupted sample from the study site also bothered to be tested with empirical equations. Rheometer and direct research at the location will be very accurate to find out the rheological properties of the sediment.

\section{ACKNOWLEDGMENTS}

This study aims to develop a 3-dimensional rectangular shape sediment trap to a vortex desilting basin sediment shape. The authors would like to thank the Ministry of Public Works and Housing for their assistance regarding the data collection required for this paper. Furthermore, the authors would also like to express their gratitude to the Research, Water Resources Engineering Research Group of the Faculty of Civil and Environmental
Engineering Institut Teknologi Bandung for supporting this publication.

\section{REFERENCES}

[1] Kuntoro A. A., Putro A. W, Kusuma M. S. B., and Natasaputra, S., The effect of land-use change to maximum and minimum discharge in Cikapundung river basin, The $3^{\text {rd }}$ International Conference on Construction and Building Engineering (ICONBUILD) 1903 pp. 100011-1,100011-7, 2017, DOI: https://doi.org/10.1063/1.5011621

[2] Kusuma, M. S. B., Rahayu, R. A., and Cahyono., Development Study of Turbulent $\kappa-$ $\varepsilon$ Model for Recirculation Flow III: Two Dimension Recirculation Flow in a Reservoir. ITB Journal of Engineering Science, Vol. 41, Issue B (1), 2009, pp. 1-16

[3] Kusuma, M. S. B., Setiawati, T., and Farid, M., Experimental Model of Dam Break Flow around several Blockages Configurations. International Journal of GEOMATE, Vol. 16, Issue 58, 2019, pp. 26-32.

[4] Gunawan, T. A., Kusuma, M. S. B., Cahyono, M., and Nugroho, J., The Application of Backpropagation Neural Network Method to Estimate the Sediment Loads. MATEC Web of Conferences 101, 2017, 05016.

[5] Adhi, R. A. and Ontowirjo, B., Evaluation of the Sediment Trap Structure Performance in the Saddang Irrigation. IOP Conf. Ser.: Earth Environ. Sci., vol. 698, no. 1, p. 012026, 2021, DOI: 10.1088/1755-1315/698/1/012026.

[6] Chaidar, A. N., Soekarno, I., Wiyono, A., and Nugroho, J, Spatial Analysis of Erosion and Land Criticality of The Upstream Citarum Watershed. International Journal of GEOMATE, Vol. 13, Issue 37, 2017, pp.133140.

[7] Papenmeier, S., Schrottke, K., Bartholoma, A., and Flemming, B. W., Sedimentological and Rheological Properties of the Water-Solid Bed Interface in the Weser and Ems Estuaries, North Sea, Germany: Implications for Fluid Mud Classification. Journal of Coastal Research, vol. 289, pp. 797-808, Jul. 2013, doi: 10.2112/JCOASTRES-D-11-00144.1.

[8] Isnaeni, M., Kusuma, M.S.B., Nugroho, Joko., Comparison of Four Particle Deposition Rate Formulae in Laminar Flow. International Journal of GEOMATE, Vol. 21, Issue 84, 2021, pp.103-111 2021

[9] Huang, Z. and Aode, H. A laboratory study of rheological properties of mudflows in Hangzhou Bay, China. International Journal of Sediment Research, vol. 24, no. 4, pp. 410424, 2009, doi: 10.1016/S10016279(10)60014-5. 
[10] Lee, C. H., Low, Y. M., and Chiew, Y. M. Multi-dimensional rheology-based two-phase model for sediment transport and applications to sheet flow and pipeline scour. Physics of Fluids, vol. 28, no. 5, p. 053305, May 2016, doi: 10.1063/1.4948987.

[11] Bowles, F. A., Faas, R. W., Vogt, P. R., Sawyer, W. B., and Stephens, K. Sediment properties, flow characteristics, and depositional environment of submarine mudflows, Bear Island Fan. Marine Geology, vol. 197, no. 1-4, pp. 63-74, Jun. 2003, doi: 10.1016/S0025-3227(03)00089-6.R.

[12] Zhang, B. Apparent viscosity of binary particle system in gas-solid separation fluidized bed. Powder Technology, vol. 387, pp. 348-353, Jul. 2021, doi: 10.1016/j.powtec.2021.04.036.

[13] Betancourt, F., Concha, F., and Uribe, L. Settling velocities of particulate systems part 17. Settling velocities of individual spherical particles in Power-Law non-Newtonian fluids. International Journal of Mineral Processing, vol. 143, pp. 125-130, Oct. 2015, doi: 10.1016/j.minpro.2015.07.005.

[14] Kelessidis, V. C. and Mpandelis, G. Measurements and prediction of terminal velocity of solid spheres falling through stagnant pseudoplastic liquids. Powder Technology, vol. 147, no. 1-3, pp. 117-125, Oct. 2004, doi: 10.1016/j.powtec.2004.09.034.

[15] Fang, Z., Zhang, Y., Zhao, S. and L. Sun. An experimental investigation on the settling velocity and drag coefficient of micrometre- sized natural, IG-110, NG-CT-10 and A3-3 graphite particles. Journal of Aerosol Science, vol. 155, p. 105774, Jun 2021, DOI: 10.1016/j.jaerosci.2021.105774

[16] Zegers, G., Mendoza, P. A., Garces, A. and Montserrat, S. Sensitivity and identifiability of rheological parameters in debris flow modelling. Nat. Hazards Earth Syst. Sci., vol. 20, no. 7, pp. 1919-1930, Jul. 2020, doi: 10.5194/nhess-20-1919-2020.

[17] Lorenzini, G. and Mazza, N. Phenomenology and Rheological Modelling. p.5, 2004.

[18] Whitehouse, R., Roberts, S. L. W. and M. J., Dynamics of Estuarine Mud. 2000. doi: 10.1680/doem.28647.

[19] Tran, A. Q., Sediment Flow Characteristics Around Cylindrical Structure Regarding Seabed Effective Stress Response. International Journal GEOMATE, vol. 18, no. 66, Feb. 2020, doi: 10.21660/2020.66.9377.

[20] Boyer, F., Guazzelli, É. and Pouliquen, O. Unifying Suspension and Granular Rheology. Phys. Rev. Lett., vol. 107, no. 18, p. 188301, 2011, doi: 10.1103/PhysRevLett.107.188301.

[21] Jop, P., Forterre, Y. and Pouliquen, O. A constitutive law for dense granular flows. Nature, vol. 441, no. 7094, pp. 727-730, Jun. 2006, doi: 10.1038/nature04801.

Copyright (C) Int. J. of GEOMATE All rights reserved, including making copies unless permission is obtained from the copyright proprietors. 